\title{
Infant Vocalizations at the First Year of Life Predict Speech Development at 2 - 7 Years: Longitudinal Study
}

\author{
Elena E. Lyakso, Olga V. Frolova, Aleksey S. Grigorev \\ Saint Petersburg State University, Saint-Petersburg, Russia \\ Email: lyakso@gmail.com
}

Received 27 June 2014; revised 18 July 2014; accepted 13 August 2014

Copyright (C 2014 by authors and Scientific Research Publishing Inc.

This work is licensed under the Creative Commons Attribution International License (CC BY).

http://creativecommons.org/licenses/by/4.0/

(c) (i) Open Access

\begin{abstract}
The authors present the results of a 7-year longitudinal study of 10 Russian children beginning at birth up to 7 years old. The relationships among vowels diverse, babbling, imitative activity during the first year of a child's life, the amount of the first words at the age of 12 months, stressed vowels duration and pitch variation in mother speech addressed to children of the first year of life, the risk of development of birth, were investigated as predictors of speech development in 2 - 7 years. The results are shown that those characteristics predicted complexity of replica in dialogues, compound phrases using, ability to retell, and reading skills formation. The risk of development at birth manifested in EEG-rhythm age immaturity in 7 years that was reflected in speech skills and reading comprehension.
\end{abstract}

Keywords

Infant's Vocalizations, Child Speech, Longitudinal Study, Risk of Development at Birth

\section{Introduction}

This predictor definition for future development is one of the pivotal areas of research on various aspects of child development in ontogenesis.

The quality of attachment to mother (Silven, 2002), the child's ability to be included in situations that requires the establishment of mutual attention with adults (Morales et al., 2000), an imitation of actions (McEwen, 2007) and maternal speech sounds (Frolova \& Lyakso, 2008), period of appearance of babbling and a variety of consonants in syllables (Stoel-Gammon, 1989; Chen \& Kent, 2005), the relationship between babbling and first words (Vihman, DePolis, \& Karen-Portnoy, 2009) are considered as prognostic features of speech development of the child in the first year of his life. 
Recent data indicate very long-term associations between infants' phonetic perception and future language and reading skills (Kuhl, 2010). Longitudinal study reveals associations between infant and parent vocalizations and later child psychiatric diagnoses as disruptive behavior disorders, oppositional-conduct disorders, attention deficit hyperactivity disorder, pervasive development disorder, and emotional disorders. These data have shown that parent-child vocalizations for 12 months can predict psychopathology in 7 years and may use as a potential risk marker for later diagnosis (Allely et al., 2013).

Many studies on a material of various languages showed different levels of formation of the speech system (phonetic, phonological, lexical-semantic, level reading and writing) (e.g. Pols et al., 2006), and analyzed their mutual influence on each other (Werker \& Tees, 2005). The issue of the link between children language skills and success in teaching them to read and to write (Fields \& Spangler, 2000; Whitehurst \& Lonigan, 1998; Muter et al., 2004) is a subject of a wider discussion.

Developing a child's reading skills is one of the stages of speech and language formation (Storch \& Whitehurst, 2002; DeThorme et al., 2010). There are now many evidences showing that children's early progress in reading skills critically depends on their oral language skills. The relative importance of different underlying skills (phonological skills, grammatical skills, and vocabulary knowledge) as predictors of reading development may change gradually and in subtle ways during the course of development. It was shown that phoneme sensitivity and letter knowledge play the critical role in the development of early word recognition skills. The significant role of vocabulary knowledge and grammatical skills for reading comprehension was demonstrated (Muter et al., 2004).

Phonemic hearing quality (Adams, Treiman, \& Pressley, 1998), education system and the child's dominant cognitive style (Das, Janzen, \& Georgiou, 2007) contribute to the formation of reading skills. A physiological indicator of child's readiness to perceive information in the learning is the maturation of brain structures, and consequently, the formation in the electroencephalogram (EEG) resting regular structure of the alpha rhythm, as the dominant form of brain activity. Intensity and rhythm localization rate give an indication of the dominance of the hemisphere in the processing of information. Cerebral functional asymmetry plays an important role in the cognitive development and cognitive style choice. Along cerebral functional asymmetry the sensorimotor asymmetry (FSA) associated with the preferred use of the hand, foot and eye develops gradually and stabilized between early and middle childhood (Gessel \& Ames, 1987).

Traditionally, the study of the formation of literacy, particularly reading skills, is considered in the context of development risks. For example, comparing the children speech development during their first five years of life, revealed a high correlation between early motor development and later mastery of language skills in children with familial risk for dyslexia, and the absence of such a link in children of the control group (Lyytinen et al. 2009). It is shown that the damage of auditory perception at birth and at 6 months of age and before schooling correlates with the difficulties in mastering the skill of reading in children, especially in the family risk for dyslexia (Leppanen et al., 2011). A correlation between the dialogic skills of children with specific language impairment (SLI) and mastery of reading comprehension skills was revealed (De Thorme et al., 2010). It was found that slower spontaneous speech with many pauses in 3-year-old children correlates with the inability of schoolage child learn reading (Smith, Locke, \& Bennett, 2008). Longitudinal 13 years long studies of families with risk for dyslexia, identified characteristics of child development that are a predictor for dyslexia (Lyytinen et al. 2009).

This introduction indicates the existence of many investigations in the field of study. They cover either a particular aspect of speech development or early speech development lags. On the other hand, longitudinal studies with a large number of measurements that identify the dependencies of each subsequent level of the child speech from a previous level of speech development are practically absent. Our previous study (Lyakso et al. 2012) on 151 children aged 4 - 7 years showed correlations between the child age, vocabulary and mastering of reading skills. The choice of children age is determined by the schooling age Russia (6 - 7 years old). The present study involved a longer development period and a wider range of measures than previous studies.

The research object is the identification of the relationship between the characteristics of vocalizations during the first year of life and the child's speech development at the age of $2-7$ years, and the identification of factors influencing the formation of different aspects of a child's speech.

\section{Method}

\subsection{Participants}

The participants of the study were 10 children (6 boys and 4 girls) aged from birth to 7 years. Information about 
the children at birth is shown in Table 1. Four infants have a neurological disorder (risk) P 91.8 in compliance with the ICD-10 scale (http://www.icd10data.com/ICD10CM/Codes/P00-P96/P90-P96/P91-/P91.8). According to the medical conclusions one child (FV) with a neurological history from birth became healthy during the first year of life, three children-during the first three years. At the age of three, all children are healthy by the medical conclusions.

Mothers' age at the time of infant's birth was $21.1 \pm 3.9$ years. None of the mothers were diagnosed with a chronic disease, nor consult a medical specialist with complaints about depression after infant's birth and during the whole period of study. Mothers have higher education ( $>16$ years), parental social status-middle class family. All families are full. The first child in families with two children had no diagnosed physical health disorders and mental development lag.

\subsection{Design and Procedures}

Infant's vocalizations and child speech were recorded: during the first three years of life-every three months, during the 4 - 7 years-every six months. Mother's speech (MS) direct to infants was recorded during the first year of an infant's life in situation "mother-infant" interaction. Video registration of infant and mother's behavior during interaction was made. The maturity of different aspects of speech was determined for children of each age group (Lyakso, 2007; Lyakso \& Gromova, 2005; Lyakso et al., 2005, 2007, 2010) (Table 2). We revealed the correlation between the characteristics of vocalizations and different parameters of speech level in older age taking into account the child age and risk.

Scope and inventory: The Kent Infant Development (KIDS) scale (for ages 0 - 15 months), Child Development Inventory (RCDI) (for ages 15 - 42 months) adapted for North-West Russia (Chistovich, Raiter, \& Sapiro, 2000), inventory of different domains (cognitive, motor, social, language, and self-help) for 3 - 7 years old children (Lyakso, 2008) were used in this study. A child's physical health was determined by a pediatrician and by a pediatric neurologist.

Speech recorded and analysis: Vocalizations and speech of children were recorded on a digital recorder "Marantz PMD660" with a "SENNHEIZER e835S" external microphone. Vocalizations during the first year of an infant's life were recorded in natural situations of interaction with the mother and in a model of 5 minute situation of interactions "face to face" and "play". The total time ranged from $40 \mathrm{~min}$ to 60 minutes. In the second year of child's life we recorded a play situation with the mother and toys. In the 3 - 4 years of a child's life the situation, when the child response to mother's questions about read the story, was used. The speech of $5-7$ years old children was recorded in situation of spontaneous speech conversations (dialogues) with adults on a given topic, retelling the text (fairy tales, cartoon and/or story), description of the plot of the picture, reading books (5 - 7 years).

The vocalizations and speech were instrumentally analyzed using a "Cool Edit" sound editor (Syntrillium Soft. Corp., USA) and PRAAT (a free software program, http://www.fon.hum.uva.nl/praat/). Duration, pitch value (F0)

Table 1. Information about infants and families at baseline.

\begin{tabular}{ccccccccc}
\hline $\begin{array}{c}\text { Infant } \\
\text { name }\end{array}$ & Gender & Gestation, weak & Weight g & $\begin{array}{c}\text { Apgar } \\
\text { score 1 min }\end{array}$ & $\begin{array}{c}\text { Apgar score } \\
5 \text { min }\end{array}$ & $\begin{array}{c}\text { ICD-10 scale } \\
\text { P 91.8 }\end{array}$ & $\begin{array}{c}\text { Child amount } \\
\text { in family }\end{array}$ & $\begin{array}{c}\text { Mother's age } \\
\text { (years) }\end{array}$ \\
\hline OZ & F & 40 & 2980 & 8 & 9 & norm & 1 & 25 \\
OR & M & 39 & 4400 & 8 & 9 & norm & 2 & 28 \\
VM & F & 40 & 3200 & 8 & 9 & norm & 1 & 24 \\
KS & M & 39 & 3950 & 8 & 9 & norm & 2 & 27 \\
KSo & F & 40 & 2680 & 8 & 9 & norm & 1 & 23 \\
LA & F & 40 & 2750 & 8 & 9 & norm & 2 & 23 \\
KV & M & 39 & 3250 & 8 & 9 & risk & 1 & 23 \\
FV & M & 41 & 3400 & 8 & 9 & risk** & 1 & 36 \\
SD* & M & 40 & 3200 & 6 & 7 & risk & 1 & 25 \\
PL & M & 40 & 2950 & 8 & 9 & risk & 1 & 24 \\
\hline
\end{tabular}

Note: *family became incomplete in the second year of life; **diagnosis dismissed at the age of 12 months; $\mathrm{f}-\mathrm{female}$; $\mathrm{m}-\mathrm{male}$. 
Table 2. Characteristics of child speech level at different age.

\begin{tabular}{|c|c|c|c|}
\hline Infant age & \multicolumn{3}{|c|}{ Characteristics of child speech level at different age } \\
\hline \multirow{8}{*}{$1 \mathrm{y}$} & \multirow{5}{*}{$\begin{array}{l}\text { Characteristics of } \\
\text { infants vocalizations } \\
\text { at } 3,6,9,12 \text { months }\end{array}$} & & $\begin{array}{l}\text { The variety of vowels and consonants in the vocalizations } \\
\text { presence at } 6,9,12 \text { months }\end{array}$ \\
\hline & & Characteristics of babbling & $\begin{array}{l}\text { Variety babbling (combination of different vowels and } \\
\text { consonants) }\end{array}$ \\
\hline & & & $\begin{array}{l}\text { The ratio babbling and other vocalizations (vowels and } \\
\text { consonants; in } 12 \text { months-words) }\end{array}$ \\
\hline & & The first words & $\begin{array}{l}\text { Amount of words: KID-scope, expert perception analysis, acoustic } \\
\text { spectrographic analysis }\end{array}$ \\
\hline & & $\begin{array}{l}\text { Infants imitation activity in } \\
\quad 3,6,9,12 \text { months }\end{array}$ & $\begin{array}{l}\text { Amount of imitation vocalizations of total vocalizations during a } \\
\text { natural situation of "mother-child" interaction, "face to face" } \\
\text { interaction situation, situation interaction with the mother and } \\
\text { toys-"play" }\end{array}$ \\
\hline & \multirow{3}{*}{$\begin{array}{l}\text { Mothers speech } \\
\text { (MS) }\end{array}$} & & The imitation of vowels, consonants, syllabic structure \\
\hline & & $\begin{array}{l}\text { Infant vocalizations and } \\
\text { word repetition }\end{array}$ & The amount of child vocalizations repeated her mother \\
\hline & & $\begin{array}{c}\text { Acoustical } \\
\text { characteristics of MS }\end{array}$ & $\begin{array}{l}\text { Stress vowel pitch values, stress vowel duration; phrase pitch } \\
\text { values (F0, F0 max-F0 min) }\end{array}$ \\
\hline \multirow{5}{*}{$2 \mathrm{y}$} & \multirow{5}{*}{ Speech level-2 y } & Whards & Amount \\
\hline & & motus & Words with different syllables amount \\
\hline & & Grammar & Single and complex phrase (amount of words) \\
\hline & & Imitation & Sounds, syllables, words \\
\hline & & $\begin{array}{l}\text { Answer to the question } \\
\text { of mother }\end{array}$ & Situation "book reading"-what the picture? \\
\hline \multirow[b]{2}{*}{$3 \mathrm{y}$} & \multirow{3}{*}{ Speech level-3 y } & Grammar & Single and complex phrase (amount of words) \\
\hline & & Repetition & $\begin{array}{l}\text { The ability to repeat and retelling mother's read text (fairy } \\
\text { tale)-single words or logical phrase }\end{array}$ \\
\hline \multirow{9}{*}{$4-7 y$} & & Dialog with adult & $\begin{array}{l}\text { Replica structure (one word, a few words, one phrase, complex } \\
\text { phrases) }\end{array}$ \\
\hline & \multirow{8}{*}{ Speech level-4 - 7 y } & Reading skills & $\begin{array}{l}\text { Ability to read words and the text ABC book and book reading } \\
\text { and understanding them }\end{array}$ \\
\hline & & $\begin{array}{l}\text { Retelling of the tale or } \\
\text { story }\end{array}$ & Logical phrase or words \\
\hline & & $\begin{array}{c}\text { Acoustical } \\
\text { characteristics }\end{array}$ & $\begin{array}{l}\text { Spontaneous speech vs. reading speech: articulation, pitch } \\
\text { values, stress vowels duration, formant triangle area }\end{array}$ \\
\hline & & Hearing & \\
\hline & & Dichotic listening test & The coefficient of lateral preference (CLP) \\
\hline & & Phonematic hearing (PH) & \\
\hline & & $\begin{array}{l}\text { Sensorimotor } \\
\text { functional asymmetry }\end{array}$ & Behavioral testing \\
\hline & & EEG & Psychological testing, EEG registration \\
\hline
\end{tabular}

and first two formant frequency values (F1, F2) were defined in infants vowel-like sounds from babbling, vowels from words of spontaneous child speech and reading speech. The duration of pauses between syllables and words in the phrase in spontaneous and reading speech was measured (Lyakso, Bednaya, \& Grigorev, 2013).

The formant triangles of vowels with the tops, corresponding to the values of the vowels [a], [u], [I], with two coordinate plots F1-F2 were built. Different pronunciation (isolated in the context of the word) is characterized by the values of the formants of vowels, which leads to different areas of the formant triangles. For examination of articulation formation in spontaneous speech and reading speech formant triangle areas were compared. This area reflects the clarity of vowels articulation. The F1-F2 planar area was computed with the following formula for the area of triangles (Vorperian \& Kent, 2007). The formula was adopted for the Russian language (Lyakso, Bednaya, \& Grigorev, 2013): 


$$
\text { Area }=0.5 *\{(\mathrm{~F} 2[\mathrm{i}] * \mathrm{~F} 1[\mathrm{a}]+\mathrm{F} 2[\mathrm{a}] * \mathrm{~F} 1[\mathrm{u}]+\mathrm{F} 2[\mathrm{u}] * \mathrm{~F} 1[\mathrm{i}])-(\mathrm{F} 1[\mathrm{i}] * \mathrm{~F} 2[\mathrm{a}]+\mathrm{F} 1[\mathrm{a}] * \mathrm{~F} 2[\mathrm{u}]+\mathrm{F} 1[\mathrm{u}] * \mathrm{~F} 2[\mathrm{i}])\}
$$

where F1[x], F2[x]-first and second formants frequency values for the appropriate vowels.

Auditory analysis: Child vocalizations and words were described perceptively by groups of native speakersexperts $(n=100$, age $=22.2 \pm 5.1$ years $)$ without auditory abnormalities. Experts listened tests and depending on the instructions noted sounds or words and/or their lexical meaning. Tests for each children speech material contain 30 vocalizations or words and phrases.

Phonetic transcription: Phonetic description of the speech material was made on the base of International Phonetic Alphabet (IPA) symbols (http://www.internationalphoneticalphabet.org). Analysis of infant vocalizations in the first year of life is the ability to describe in terms of IPA sounds of children.

Grammar: In speech material the syntactic structure of the child's response replicas in dialogue with adults (one word, simple phrase, a few phrases) was determined. The grammar phrase's structure was ascertained. The number of words in a replica was counted.

Reading skills: The ability of the child to read material of varying difficulty (letters, syllables, words and phrases) ABC book and text stories was tested. The degree of formation of the children focus on the meaning of the text and the quality of understanding of words and phrases, using the procedure of selection of illustrations to read words and phrases was examined (Lyakso et al., 2010). Clarity pronouncing words when reading was determined based on instrumental spectrographic analysis of speech material (Lyakso, Bednaya, \& Grigorev, 2013).

Dichotic listening test: To estimate the right-left hemisphere of children with hearing dichotic testing was conducted. During the dichotic listening test is presented with two different words simultaneously. The different stimuli are directed into different ears over headphones "HD 415" using editor "Cool Edit Pro 2.1". Children’s were instructed to repeat aloud the words they heard in one ear. The child words were recorded on "Marantz PMD660”. The stimulus was 60 words couples. The time interval between pairs of words was 3 sec.

The coefficient of lateral preference (CLP) was calculated as: CLP $=(\mathrm{R}-\mathrm{L}) * 100 /(\mathrm{R}+\mathrm{L})$ (in \%), where $\mathrm{R}$ - the number of "right-choice"-words spoken by the child of the stimuli applied to the right ear; L-number of "left choice"-words spoken by the child of the stimulus applied to the left ear. CLP: range from $-10 \%$ to $+10 \%$ ambivalence; less than 10\% left-hand preference (dominance of the right hemisphere); more than $10 \%$ right preferences (dominance of the left hemisphere).

Focus sensorimotor asymmetry: Focus sensorimotor asymmetry (FSA) was determined by tests, including 10 standard set of tasks to detect the use leading hands, feet, eyes and ears. For each child the asymmetry coefficient for each job and the overall rate of all tasks was considered.

Audiometry: Auditory perception in children by the method of audiometry was defined. Used single-channel clinical audiometer tone “Maico AD229E”, in the frequency range 125 - $8000 \mathrm{~Hz}$, intensity from -10 dB to 120 $\mathrm{dB}$.

EEG registration and analysis: The technique of children's brain electric activity (EEG) registration was approved. We used a standard arrangement of electrodes by system 10 - 20. EEG analysis was carried out by program block "EEG-2000”, version 3.0. Spectral analysis was made with EEG fragments in average length about 6 s; a period was 2 s, without overlapping Hanning windows graduation. Estimated characteristics of alpha rhythm were frequency, asymmetry and localization. The psychophysiological status of the child carried his psychological testing, including assessment of the level of anxiety and on children's drawings (a modification of the test "Kindergarten") was determined before EEG registration. The index of anxiety (IA) as the number of negative election to the total number of elections ( $n=14$ elections), in percent was determined. Child's emotional state (ES) immediately before registration of EEG was determined by selecting them for drawing flowers and picture stories.

A statistical analysis was made in "Statistica 10”, with using of ANOVA, Mann-Whitney, Wilcoxon, Fisher tests, Spearman correlation, Multiple Regression analysis, and Discriminant analysis.

Ethical approval was obtained from the Ethics Committees (Health and Human Services (HHS) (IRB 00003875 St. Petersburg State University IRB\#1-Behavioral) and Local Committee.

\section{Result}

A negative correlation between gestational age and weight at birth of the child $(r=-0.47, p<0.01)$, a positive correlation between Apgar scores at birth and inventories and scales, determining the development of children 
aged from birth to 7 years $(r=0.31, p<0.05)$ were determined.

Physiological parameters at birth and characteristics of infant vocalizations in 12 months amounted to 11 variables for Factor analysis. Three factors with following factors loadings were extracted (Figure 1). Factor 1: age (0.780), a variety of vowels (0.857), babbling (0.783), imitation activity (0.925), the amount of the first words (0.925). This factor reflects the degree of "progress" in early speech development of the child. Factor 2: gender differences $(0.802)$, gestational age $(-0.710)$ and weight $(0.881)$. Factor 3: risk $(0.826)$ and Apgar scores (0.735). The next two factors mainly reflect the physiological condition of the child during the first year of life and his gender identity. Only the first year of age showed higher levels of nonverbal vocalizations in girls vs. boys.

The 12 months old infants by the number of first words were divided into two groups. The first group $(\mathrm{n}=5)$ included children (OZ, OR, VM, KV, FV) with a repertoire of four or more words (4 - 9 words). Maximum words ( 9 words) were found in the repertoire of the child with the risk of development (KV). The second group $(n=5)$ included children (KS, KSo, LA, SD, PL) the repertoire of which with less than four words ( 0 - 3 words). Both groups included two children at risk of developing.

Significant correlation between the number of words in the repertoire of 12 month old infants and frequency of infant vocalizations, imitated by the mother in a model situation "play" in the child's age of 9 months $(\mathrm{r}=$ $0.57, p=0.022$ by Spearman correlation) and 12 months $(\mathrm{r}=0.52, p=0.039)$ was found. Based on perceptual and instrumental analysis, it was shown that children of the two groups differed in the characteristics of imitation vocalizations. Experts better (probability 0.75 ) recognize vowels ( $p<0.05$; at 3 and 12 months) and consonants ( $p<0.01 ; 0.01$-respectively at 6 and 12 months) in children imitating vocalizations of the first group than the second group. During the imitation mother's voice the infants from the first group more clearly repeated vowels and consonants that allow the experts to recognize them with high probability.

Duration of vowels in the words of MS addressed to 3-month-old infant's correlates with the infant's imitation activity in 12 months $(0.8163)$ was shown. Imitation activity correlates with amount of first words at 12 months (0.861), with a variety of vowels (0.666) and babbling (0.816).

The following correlation among the child speech level at 12 months and 24 months were found between: the number of words in the repertoire of children aged 12 months and 24 months $(r=0.9289, p=0.007)$; the number of words in the repertoire of children aged 12 months and the number of words consisting of more than three syllables in 24 months $(r=0.7615, p=0.0214)$.

In the second year of child life, the following correlation between the speech skills development and MS address children were found between: the number of child vocalizations, imitated by mother in "play" interaction situation with infants aged 9 and 12 months, and the number of words in the repertoire of children aged 24 months ( $\mathrm{r}=0.7112 ; p=0.0268, \mathrm{r}=0.7545, p=0.0368$-respectively for child age 9 and 12 months); the number of words in the repertoire of the child's in 24 months and the frequency of child's imitation of mother's words in 21 months $(r=0.7043, p=0.0268)$; the number of words in the repertoire of the child in 24 months and the number of 15 months old and 18 months old infant vocalizations, imitated by mother $(\mathrm{r}=0.8696, p=$ $0.0022 ; \mathrm{r}=0.7538, p=0.0149$, respectively for child age 15 and 18 months).

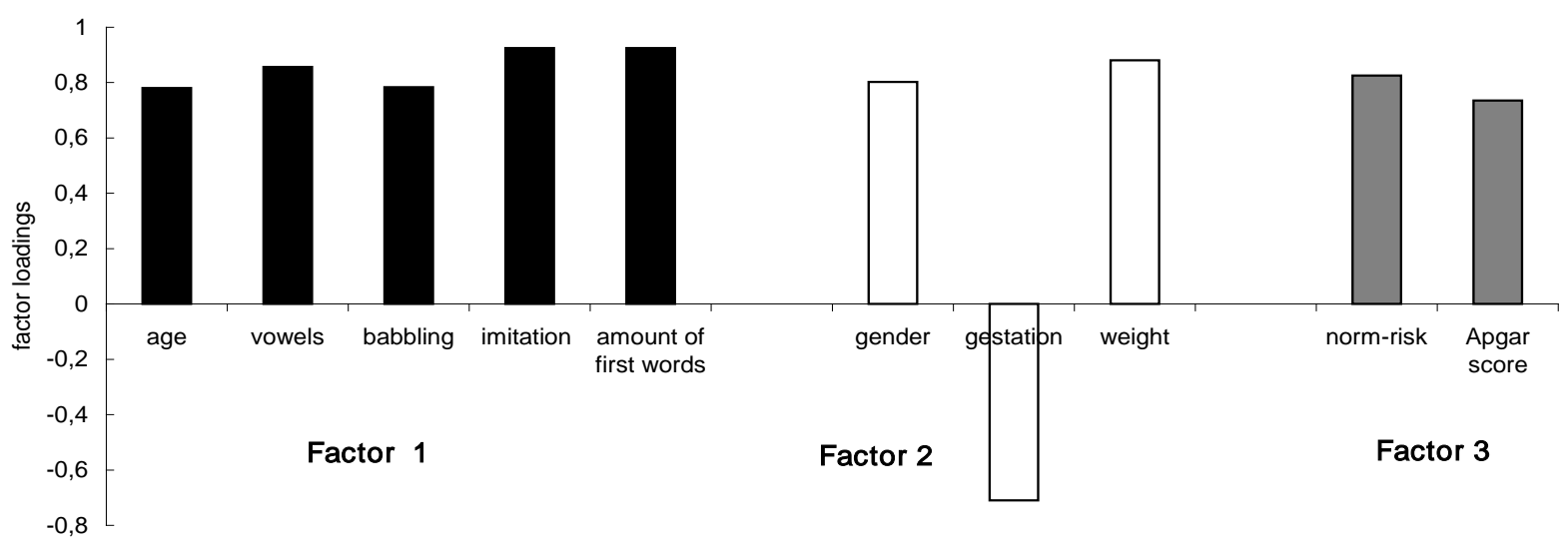

Figure 1. Physiological characteristics and the level of vocal development during the first year of an infant's life. 
There were significant correlations between the characteristics of the MS addressed to 3 months old infants and 12 months old infants and the characteristics of the speech development of children aged 1 - 7 years (Table 3 ). MS significant characteristics were stressed vowel duration in the word and the range of the pitch frequency phrases addressed to the child.

The age of the child is correlated with all features reflecting the complicated levels of language/speech development:

with a variety of syllables ( $\mathrm{r}=0.65, p<0.01)$, vowels $(\mathrm{r}=0.49, p<0.01)$, imitation activity $(\mathrm{r}=0.73, p<$ $0.01)$, the amount of first words at 12 months $(\mathrm{r}=0.44, p<0.01)$;

with speech characteristics of the child in two years $(\mathrm{r}=0.84, p<0.01)$; correlation with the answers to questions when reading her mother's books at 2 - 3 years $(\mathrm{r}=0.85, p<0.01)$;

a retelling of the story in $4-7$ years $(r=0.80 ; r=0.83 ; r=0.82, p<0.01$-respectively a word, a phrase, a few sentences); using replicas in the dialogue $(r=0.72 ; r=0.83 ; r=0.80 ; r=0.81, p<0.01-$ respectively replicas standing of one word, one phrase, complex sentences, a few sentences); description pictures ( $\mathrm{r}=0.82, p<$ $0.01)$; the formation of the reading sills $(\mathrm{r}=0.64, p<0.01)$ and reading comprehension $(\mathrm{r}=0.61, p<0.01)$.

These data indicate that the increasingly complex dynamics of the speech comprehension skills of the child and confirm the general way of development.

Analysis of reading skills mastering showed that at the age of 4 years none of the children could read. At five years all the children (exception child PL) learned letters and began to read some syllables in ABC book. One child could fluently read words by syllables and simple sentences (LA). At age of 7 years, children could fluently read words and phrases by syllable and understood reading material. Children with developmental risk (during the first three years of life) had difficulty with reading comprehension at age of 7 years (exception-child FV).

The dynamics of temporal and spectral characteristics of the stressed vowels in spontaneous speech and reading were analyzed as a criterion for the "technical" side of reading skills mastering. At the stage of development of a child's reading skills (reading the letters, individual syllables -5 years) duration and value of the first two formants frequency of vowels in reading significantly higher than in spontaneous speech (Figure 2).

Vowel duration and vowel acoustic space with reading words by syllables do not differ in a child age 6 and 7 years. When 7-year-old children read phrases, vowel duration $(p<0.05)$ and vowel acoustic space stressed vowels $(p<0.05)$ are higher in reading than in spontaneous speech (Figure 2(A), Figure 2(B)). By the age of 7 years, children decrease pauses in reading between syllables in words $(p<0.01)$ and between words in a phrase $(p<0.05)$. A significant correlation between the child's age and the duration of stressed vowels in words $(\mathrm{r}=$ 0.065, $p<0.01)$; correlation between age and the spectral characteristics of vowels $(\mathrm{r}=0.069, p<0.01)$, child age and duration of pauses between syllables in words $(\mathrm{r}=0.069, p<0.01)$ were found.

Phonemic hearing (PH) examination revealed no difficulty for all children in a situation of choice of the sequence of images (pictures) corresponding to the proposed to child pair of words/koza-kosa/ (/goat-plait/).

CLP (dichotic test) for 7 children ranged from 15\% to 64\% - the dominance of the left hemisphere for speech; two children (OZ, FV) showed FSA $=-61 \%$ and $-24 \%$ respectively of the right hemisphere dominance for speech, one child (OR) had CLP 7\%-ambivalence. Lateral profile (CLP + PH) in children norms and risk is not significantly different.

Correlation analysis included 15 parameters that reflect the physiological and psychophysiological condition of the child and the reading skills and comprehension for 6.5 - 7.0 year-old. Significantly higher correlation established between 8 parameters (Table 4).

Child physiological and psychophysiological parameters and reading skills was amounted to 15 variables for Factor analysis. The following one factor was extracted (Figure 3). This factor shows that the risk at the birth related (positively) with the reading skills, reading comprehension at 6.5 - 7 years and immaturity EEG rhythm in brain activity. Characteristics reflecting the asymmetry on dichotic test (CLP) and localization of EEG rhythms (left sided preference CLP for dichotic test and EEG asymmetry focus-left-handed) are negatively correlated with the risk of development.

Risk at birth as a predictor EEG-rhythm in 7 years $(\mathrm{F}(1.8)=22.871, p<0.00139$, std.er: 0.27883-Multiple Regression analysis, and according Discriminant analysis $(\mathrm{F}(1.8)=22.87, p<0.001)$.

All characteristics of the speech development of children during the seven years of life, physiological indicators at birth, psychophysiological skills obtained while testing children aged 4 - 7 years, were the basis for the Spearmen correlation analysis. Factor analysis based on 42 variables identified 4 factors with 20 variables (Figure 4). 
Factor 1: developmental risk (0.875), EEG data-rhythm (0.846), EEG-asymmetry $(-0.856)$ and characteristics of child speech level in 2 years (0.915), phrases in the child's active lexicon at 3 year (0.702), reading skills at 5 years $(0.728)$ and at 6 years (0.783); and answer one phrase replica at 5 years $(-0.708)$. Factor 2 involved cha-

Table 3. Correlations of the Measure: characteristics mothers speech vs. child speech.

\begin{tabular}{|c|c|c|c|c|}
\hline \multicolumn{2}{|c|}{ Mother speech } & \multicolumn{3}{|c|}{ Child speech skills } \\
\hline Direct to infants & Characteristics & Child age & Characteristic & Correlation \\
\hline \multirow{6}{*}{$3 \mathrm{~m}$} & \multirow{6}{*}{ Stress vowel duration } & \multirow{3}{*}{$1 \mathrm{y}$} & Babbling & $0.621 *$ \\
\hline & & & First words & $0.620^{*}$ \\
\hline & & & Imitation-1 y & $0.816^{* *}$ \\
\hline & & $2 \mathrm{y}$ & Imitation-2 y & $0.634^{*}$ \\
\hline & & $3 y$ & Retelling mother’s & $0.654^{* *}$ \\
\hline & & $6 y$ & Picture description & $0.655^{* *}$ \\
\hline \multirow{4}{*}{$12 \mathrm{~m}$} & \multirow{2}{*}{ Stress vowel duration } & $5 y$ & Replica-one word & $0.677^{* *}$ \\
\hline & & $6 \mathrm{y}$ & Reading & $-0.707^{* *}$ \\
\hline & \multirow{2}{*}{$\begin{array}{l}\text { Phrase pitch values } \\
\quad\left(\mathrm{F} 0_{\max }-\mathrm{F} 0_{\min }\right)\end{array}$} & \multirow{2}{*}{$7 y$} & Replica-complex phrase & $-0.715^{* *}$ \\
\hline & & & Replica-one phrase & $0.677^{* *}$ \\
\hline
\end{tabular}

Note: ${ }^{*} p<0.05 ;{ }^{* *} p<0.01$ Spearman correlation.

Table 4. Intercorrelation of the measures: child physiological and psychophysiological parameters and reading skills.

\begin{tabular}{|c|c|c|c|c|c|c|c|c|c|}
\hline & Characteristics & 1 & 2 & 3 & 4 & 5 & 6 & 7 & 8 \\
\hline 1 & Risk & - & & & & & $0.857 * *$ & & \\
\hline 2 & KID & & - & $-0.756^{* *}$ & & & & & \\
\hline 3 & CLP (dichotic test) & & $-0.763^{* *}$ & - & & & & & \\
\hline 4 & Reading & & & & - & $0.673^{* *}$ & & $-0.750^{* *}$ & \\
\hline 5 & Reading comprehension & & & & $0.673^{* *}$ & - & $0.636 * *$ & & \\
\hline 6 & EEG-rhythm & $0.857 * *$ & & & & $0.635^{* *}$ & - & & \\
\hline 7 & EEG-asymmetry & & & & $-0.750 * *$ & & & - & $-0.692 * *$ \\
\hline 8 & ES & & & & & & & $-0.692 * *$ & \\
\hline
\end{tabular}

Note: $* * p<0.01$ Spearman correlation.
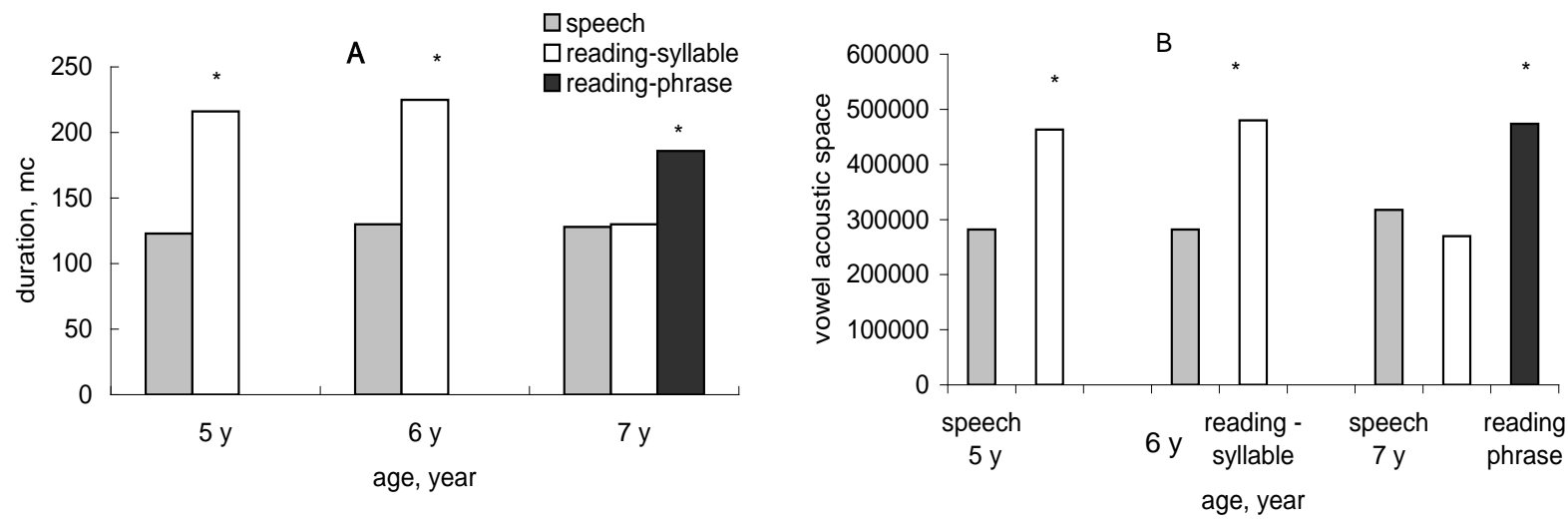

Figure 2. Vowels durations (A) and vowels acoustic space (B) in the spontaneous speech and reading speech of children aged $5-7$ years. ${ }^{*} p<0.05$ mann-whitney criterion. 


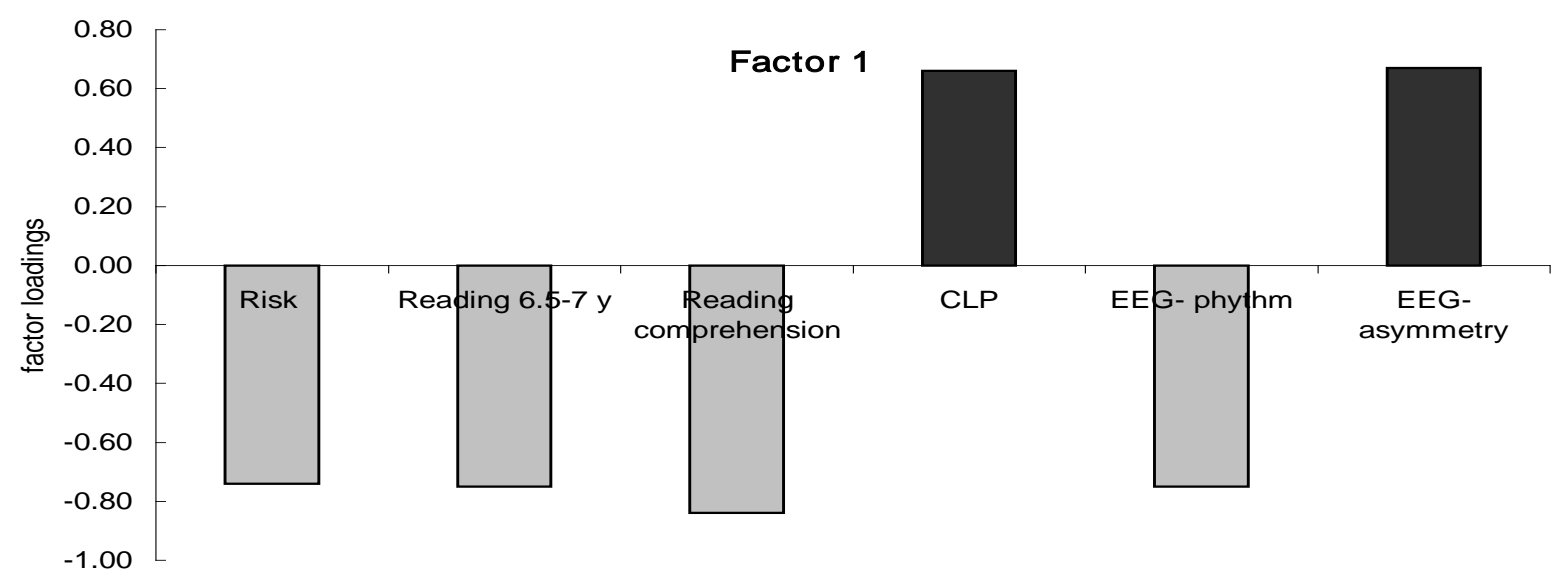

Figure 3. One factor indicates correlation between child physiological and psychophysiological parameters and reading skills. Factor loadings $>0.7$.

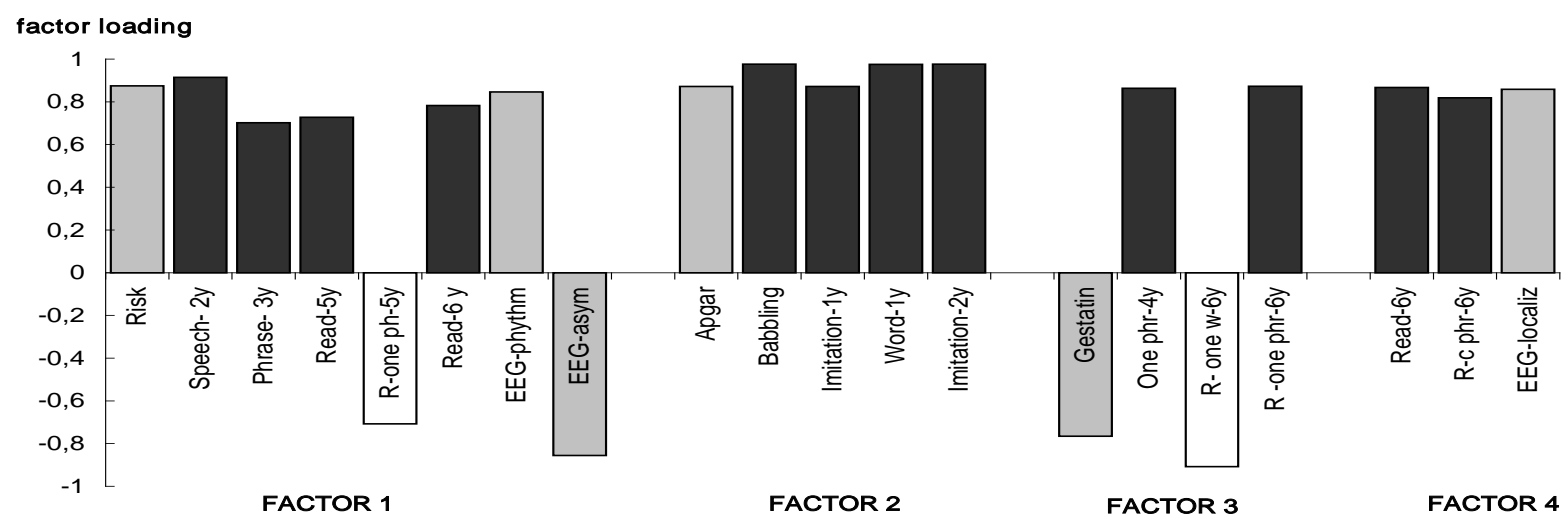

Figure 4. Distribution factors in the analysis of indicators characterizing the physiological condition of the child at birth, and level of language development from 3 months to 7 years.

racteristics of infants vocal development mainly during first year of life: babbling (0.976), first words (0.976), imitation activity (0.872; 0.976 - correspondence at first and second years of life); and Apgar score at birth (0.872). Factor 3: shown that gestation $(-0.766)$ and replica with one word at 6 years $(-0.908)$ have negative factor loading vs. one phrases speech at 4 years (0.863) replica with one phrases at 6 years (0.873). Factor 4 characterizes the higher language level at 6 years: reading skills $(0.867)$, replica with complex phrases $(0.819)$ and localization EEG rhythm in brain regions (0.859).

Multivariate analysis: When factors age, risk and their combination (Age and Risk), quantity of words pronounced by 12 months old child were selected we revealed the influence of these factors on the later characteristics of the speech development. Factor that determines the interaction of the child status in the first year of life (norm vs. risk) and the age of child (risk + age) affects the child's understanding of the reading material $\mathrm{F}(5,59)$ $=3.0, p=0.001$ (ANOVA).

When each of these factors were taken in account separately (factor-risk and factor-age) it was shown that in 5 years answer replica of one word in dialogue with adults were significantly more frequently at risk children than at the norm $(p<0.05)$; norm children used complex sentences significantly often $(p<0.001)$ than risk children. In the 6.5 - 7 years, factor-risk affects the use by children of several phrases in response cue in the dialogue with adults, more phrases in response cue in norm children $(p<0.01)$ than in risk. Thus, the risk of development defined at infant's birth, correlates with the response cues in conversations with adults in the older age of the child.

Multivariate analysis ANOVA: Vowels variety in 12 month old infant's vocalizations affects on picture description by complex phrases in $4-6$ years old child $(\mathrm{F}(1.29)=4.3, p=0.048)$. Number of first words at 12 
months affects use in the retelling single simple phrases in 4 years $(\mathrm{F}(5,29)=3.27, p=0.023)$, and in complex sentences replica in all children aged $4-7$ years in dialogues with adults $(\mathrm{F}(1,59)=4.83, p=0.0032$ multivariate analysis ANOVA).

\section{Discussion}

This longitudinal study has shown that the development of different aspects of speech correlates with infant vocalization characteristics and physiological state of infant. We found the correlation between the specific characteristics of speech development at an early age with different child's speech characteristics at an older age. Developmental risk at infant birth as a predictor for brain activity at 7 years was shown. These findings may seem obvious, but it should be borne in mind that at the age of three, all children were considered developing normally according to medical conclusion.

It is noteworthy that in our study, children were classified as high risk only based on health indicators, but all infants were full term and had a normal weight. They were grown up in two-parent families, the mother did not suffer from depression. It is well known that preterm birth is a risk factor for psychiatric morbidity in childhood, adolescence and young adulthood (Johnson \& Marlow, 2011). Increased risk has also been reported in adults born at term with low birth weight, characterized as small for gestational (Vasiliadis et al., 2010). Low birth weight has been found to be a risk factor for later development of psychiatric disorders (Lund et al., 2012). The volume of the active vocabulary of the child aged 1 - 3 years is negatively correlated with the level of maternal depression and positive-with the volume of the parent dictionary (Pan et al., 2005). Mothers of children participated in the study, changed the characteristics of voice in situation of interaction with infants. Maternal speech had a positive impact not only on the development of vocalizations in infants, but also on the complexity of speech of children aged 2 - 6 years.

Children at risk of development at birth have a lower level of vocalizations in the first year of life, which confirms previous findings (Lyakso, 2007), but differ from their peers without neurological disorders, using simple phrases, and one-word responses replicas in dialogues with an adult at the age of $5-7$ years. Risk at birth affects the child's ability to detailed answer to a question that may indirectly indicate a lag cognitive development. This assumption is confirmed by information that speech disturbances, leading to communication block should be considered as an integral part of the overall mental and cognitive development of the child (Law \& Plunkett, 2009).

For the first time Russian material shows a statistically significant association of certain characteristics of the speech development of the child in the age dynamics. Clear pronounced vowels and consonants, the number of first words at 12 months are predictors of speech development of the child at the older age.

Children imitation activity in the first two years of life is an important parameter. Other researchers point to the correlation between the volume of the active vocabulary of the child of two year-old and his imitative abilities (McEwen, 2007). It was shown that the 6, 8, 10, 12, 18 old month's infant imitation activity is directly connected with the establishment of joint attention with adults, and correlates with the development of children's active vocabulary in the third year of life (Morales et al., 2000).

The data about the reading skills measured by comparing the acoustic characteristics of reading and spontaneous speech, reading and understanding of the child showed that the factors of age and progress of speech skills and reading skills are related in normally developing children. Children at risk of development at birth have trouble understanding the reading material, but do not differ from normally developing children by temporal and spectral characteristics of reading and spontaneous speech, which is further evidence of the impact of the birth risk on a child's cognitive development.

We considered reading skills as a stage of speech development of a child of preschool age. Speaking of reading, we took into account the "technical" side-articulation forming in reading and reading comprehension. The method of selection of illustrations to determine the child's understanding of reading material, a description of the picture and making a story from it, retelling tales or cartoon gives an indication not only of speech, but also on cognitive development of the child at the time of the development of their reading skills. In spite of the small sample of children studied there were significant differences between children with a birth risk characteristics and norms of their speech development and cognitive component of reading skills (reading comprehension). Explanation can serve as physiological data. An increase in the activity in the frontal areas of the brain of 18 30 month old infants in a situation where a mother is reading a picture book to them, compared with passive 
viewing videos reading stories, was shown (Ohgi, Loo, \& Mizuike, 2010).

The risk of development at birth influences the processes of morphofunctional maturation of brain structures and may lead to increase of maturation and specific functional organization of different brain areas. In particular, the phonological processing, revealed bilateral reduction of activity in the occipital-temporal region and the left side in the parietal-temporal region of the brain in children of 5 - 5.5 years old with a family risk for dyslexia, compared with the control (Raschle, Zuk, \& Gaab, 2012). In the normal development children aged 5 - 6 years and 7 - 8 years occur morphofunctional transforming structures of the cerebral cortex of the brain involved in cognitive processes (Moore, 2002), and brain mechanisms provide verbal activity are founded.

We have shown the influence of risk factors at birth on the formation of different aspects of the speech of the child at different ages, including the formation of reading skills. On the other hand, the results of our study confirm the idea that mastery of spoken language and reading skills is a single process of speech development (DeThorme, 2010), but the relationship between these two skills is not linear in time (Storch \& Whitehurs, 2002).

\section{Conclusion}

Complexity of replica in dialogues, compound phrases using, ability to retell, reading skills formation, as stages of child speech development, reflect a complex dynamic process that begins at the preverbal stage of development, which are affected by the physiological condition of the child at birth.

Predicts of speech development at 2 - 7 years are vowels diversity, babbling, imitation activity during the first year of a child's life, the amount of the first words at the age of 12 months, stressed vowels duration and pitch variation in mother speech addressed to children of the first year of life. The risk of development at birth, manifested in EEG-rhythm age immaturity in 7 years that was reflected in speech skills and reading comprehension.

\section{Acknowledgements}

This research is supported by the Russian Fund for Humanities (Project No. 13-06-00041a), Russian Foundation for Basis Research (Project No. 13-06-00281a).

\section{References}

Adams, J., Treiman, R., \& Pressley, M. (1998). Reading, Writing, and Literacy. In I. E. Sigel, \& K. A. Renninger (Eds.), Handbook of Child Psychology: Child Psychology in Practice (pp. 275-355). New York: Wiley.

Allely, C. S., Purves, D., McConnachie, A., Marwick, H., Johnson P., Doolin O., Puckering C., Golding J., Gillberg C., \& Wilson, P. (2013). Parent-Infant Vocalizations at 12 Months Predict Psychopathology at 7 Years. Research in Developmental Disabilities, 34, 985-993. http://dx.doi.org/10.1016/j.ridd.2012.11.024

Chistovich, I., Reiter, J., \& Shapiro, Y. (2000). Rukovodstvo po Ocenke Razvitiya Mladencev do 16 Mesyacev na Osnove Rusificirovannoy Shkaly KID (Assessment of Babies Development up to the Age of 16 Months on the Basis of the Russified KID-Scale). Saint-Petersburg, Russia: Saint-Petersburg Institute of Early Intervention.

Das, J. P., Janzen, T., \& Georgiou, G. K. (2007). Correlates of Canadian Native Children's Reading Performance: From Cognitive Styles to Cognitive Processes. Journal of School Psychology, 45, 589-602. http://dx.doi.org/10.1016/j.jsp.2007.06.004

De Thorme, L. S., Petrill, S. A., Schatcheneider, C., \& Cutting, L. (2010). Conversational Language Use as a Predictor of Early Reading Development: Language History as a Moderating Variable. Journal of Speech, Language, and Hearing Research, 53, 209-223. http://dx.doi.org/10.1044/1092-4388(2009/08-0060)

Fields, M. V., \& Spangler, K. L. (2000). Let’s Begin Reading Right: A Developmental Approach to Beginning Literacy. Upper Saddle River, NJ: Merrill.

Frolova, O. V., \& Lyakso, E. E. (2008). Vocal-Speech Imitation Developmental Changes in Russian Mother-Child Dyads and Orphans. Proceedings from the XI Congress of the International Association for the Study of Child Language, Edinburgh, 28 July-1 August 2008, 2-15.

Gessel, A., \& Ames, L. (1987). The Development of Handedness. Journal of Genetic Psychology, 70, 155-175.

ICD-10 Scale (2014) http://www.icd10data.com/ICD10CM/Codes/P00-P96/P90-P96/P91-/P91.8

IPA. http://www.internationalphoneticalphabet.org

Johnson, S., \& Marlow, N. (2011). Preterm Birth and Childhood Psychiatric Disorders. Pediatric Research, 69, 11R-18R. http://dx.doi.org/10.1203/PDR.0b013e318212faa0 
Kuhl, P. K. (2010). Brain Mechanisms in Early Language Acquisition. Neuron, 67, 713-727. http://dx.doi.org/10.1016/j.neuron.2010.08.038

Law, J., \& Plunkett, C. (2009). EPPI-Centre Report: The Interaction between Behaviour and Speech and Language Difficulties: Does Intervention for One Affect Outcomes in the Other? London: EPPI-Centre Social Science Research Unit Institute of Education University of London.

Leppanen, P. H. T., Hamalainen, J. A., Guttorm, T. K., Eklund, K. M., Salminen, H., Tanskanen, A. et al. (2011). Infant Brain Responses Associated with Reading-Related Skills before School and at School Age. Clinical Neurophysiology, 42, 35-41. http://dx.doi.org/10.1016/j.neucli.2011.08.005

Lyakso, E. (2007). Early Speech Development in Children Developing Normally and Children with Prenatal and Early Postnatal Disorders: A Longitudinal Study. Proceedings of the Word Congress Prenatal Child and Society. Role of Prenatal Psychology in Obstetrics, Neonatology, Psychotherapy, Psychology and Sociology, Moscow, 20-24 May 2007, 186-188.

Lyakso, E., Frolova, O., Smirnov, A., Kurazova, A., \& Grigorev, A. (2012). Speech Development Level of Children at the Stage of Reading Skills Formation. Psychology Journal, 33, 73-87. (in Russian)

Lyakso, E., \& Gromova, A. (2005). The Acoustic Characteristics of Russian Vowels in Children of 4 and 5 Years of Age. Psychology of Language and Communication, 9, 5-14.

Lyakso, E., Gromova, A., Frolova, O., \& Romanova, O. (2005). Acoustic Aspect of the Formation of Speech in Children in the Third Year of Life. Neuroscience and Behavioral Physiology, 35, 573-583. http://dx.doi.org/10.1007/s11055-005-0096-z

Lyakso, E. (2008). Estimation of Early Speech and Cognitive Development: Development and Testing of the Inventory. In T. N. Ushakova (Ed.), Child's Speech-Problems and Solutions (pp. 318-362). Moscow: Psychology Institute, RAS.

Lyakso, E., Bednaya, E., \& Grigorev, A. (2013). Auditory and Spectrographic Analysis of the Words of 2-8 Years-Old Russian Children. In M. Zelezny, I. Habernal, \& A. Ronzhin (Eds.), Lecture Notes in Computer Science (pp. 54-61). New York: Springer Verlag.

Lyakso, E. E., Ushakova, T. N., Frolova, O. V., Kurazhova, A. V., Bednaya, E. D., Gaikova, J. S., Grigoriev, A. S., Soloviev, A. N., \& Ostrouchov, A. V. (2010). Russian Children's Vocabulary, Speech Imitation and Reading Skills Mastery. International Journal of Psychophysiology, 77, 310. http://dx.doi.org/10.1016/j.ijpsycho.2010.06.215

Lyytinen, H., Erskine, J., Kujala, J., Ojanen, E., \& Richardson, U. (2009). In Search of a Science-Based Application: A Learning Tool for Reading Acquisition. Scandinavian Journal of Psychology, 50, 668-675. http://dx.doi.org/10.1111/j.1467-9450.2009.00791.x

McEwen, F., Happe, F., Bolton, P., Rijsdijk, F., \& Ronald, A. (2007). Origins of Individual Differences in Imitation: Links with Language, Pretend Play, and Socially Insightful Behavior in Two-Year-Old Twins. Child Development, 78, 474-492. http://dx.doi.org/10.1111/j.1467-8624.2007.01010.x

Moore, J. K. (2002). Maturation of Human Auditory Cortex: Implication for Speech Perception. Annals of Otology, Rhinology \& Laryngology, 189, 7-10.

Morales, M., Mundy, P., Delgado, C. E. F., Yale, M., Messinger, D., Neal, R., \& Schwartz, H. K. (2000). Responding to Joint Attention across the 6- through 24-Month Age Period and Early Language Acquisition. Journal of Applied Developmental Psychology, 21, 283-298. http://dx.doi.org/10.1016/S0193-3973(99)00040-4

Muter, V., Hulme, C., Snowling, M. J., \& Stevenson, J. (2004). Phonemes, Rimes, Vocabulary, and Grammatical Skills as Foundations of Early Reading Development: Evidence from a Longitudinal Study. Developmental Psychology, 40, 665681. http://dx.doi.org/10.1037/0012-1649.40.5.665

Ohgi, S., Loo, K. K., \& Mizuike, C. (2010). Frontal Brain Activation in Young Children during Picture Book Reading with Their Mothers. Acta Paediatrica, 99, 225-229.

Pan, B. A., Rowe, M. L., Singer J. D., \& Snow C. E. (2005). Maternal Correlates of Growth in Toddler Vocabulary Production in Low-Income Families. Journal of Child Development, 76, 763-782.

Pols, L. C. W., Lyakso, E., van der Stelt, J. M., Wempe, T. G., \& Zajdó, K. (2006). Vowel Data of Early Speech Development in Several Languages. Multiling. http://www.isca-speech.org/archive/ml06/ml06_010.html

Raschle, N. M., Zuk, J., \& Gaab, N. (2012). Functional Characteristics of Developmental Dyslexia in Left-Hemispheric Posterior Brain Regions Predate Reading Onset. Proceedings of the National Academy of Sciences of the United States of America, 109, 2156-2161. http://dx.doi.org/10.1073/pnas.1107721109

Silven, M. (2002). Something from Nothing. Early Interaction and Language Acquisition in Finnish Children: Cascading Effect from First Words to Reading? Ph.D. Thesis, Turku: Turin Yliopisto.

Smith, A. B., Locke, J. L., \& Bennett, J. (2008). A Longitudinal Study of Speech Timing in Young Children Later Found to Have Reading Disability. Journal of Speech, Language, and Hearing Research, 51, 1300-1314. http://dx.doi.org/10.1044/1092-4388(2008/06-0193) 
Stoel-Gammon, C. (1989). Prespeech and Early Speech Development of Two Late Talkers. First Language, 9, 207-223. http://dx.doi.org/10.1177/014272378900900607

Storch, S. A., \& Whitehurst, G. J. (2002). Oral Language and Code-Related Precursors to Reading: Evidence from a Longitudinal Structural Model. Developmental Psychology, 38, 934-947. http://dx.doi.org/10.1037/0012-1649.38.6.934

Vasiliadis, H. M., Buka, S. L., Martin, L. T., \& Gilman, S. E. (2010). Fetal Growth and the Lifetime Risk of Generalized Anxiety Disorder. Depression and Anxiety, 27, 1066-1072. http://dx.doi.org/10.1002/da.20739

Vihman, M. M., DePolis, R. A., \& Karen-Portnoy, T. (2009). A Dynamic Systems Approach to Babbling and Words. In E. Bavin (Ed.), Handbook of Child Language (pp. 163-182). Cambridge: Cambridge University Press. http://dx.doi.org/10.1017/CBO9780511576164.010

Vorperian, H., \& Kent, R. (2007). Vowel Acoustic Space Development in Children: A Synthesis of Acoustic and Anatomic Data. Journal of Speech, Language, and Hearing Research, 50, 1510-1545. http://dx.doi.org/10.1044/1092-4388(2007/104)

Werker, J. F., \& Tees, R. C. (2005). Speech Perception as a Window for Understanding Plasticity and Commitment in Language Systems of the Brain. Developmental Psychobiology, 46, 233-251. http://dx.doi.org/10.1002/dev.20060

Whitehurst, G. J., \& Lonigan, C. J. (1998). Child Development and Emergent Literacy. Child Development, 69, 848-872. http://dx.doi.org/10.1111/j.1467-8624.1998.tb06247.x 
Scientific Research Publishing (SCIRP) is one of the largest Open Access journal publishers. It is currently publishing more than 200 open access, online, peer-reviewed journals covering a wide range of academic disciplines. SCIRP serves the worldwide academic communities and contributes to the progress and application of science with its publication.

Other selected journals from SCIRP are listed as below. Submit your manuscript to us via either submit@scirp.org or Online Submission Portal.
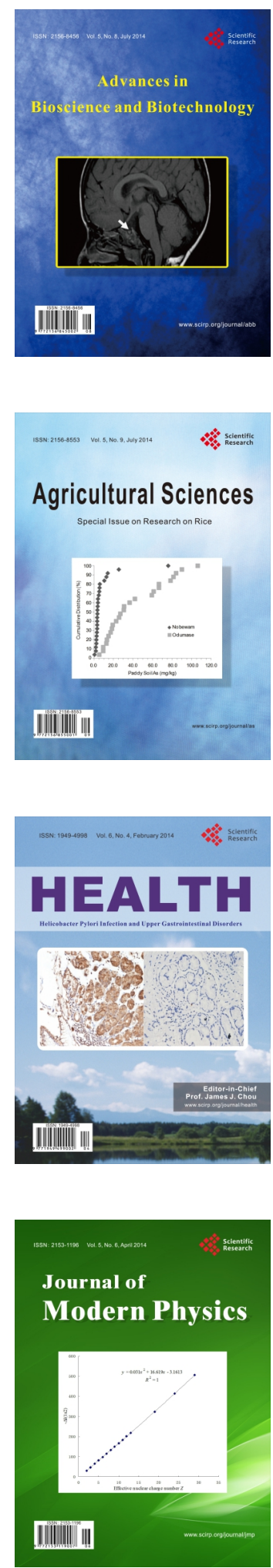
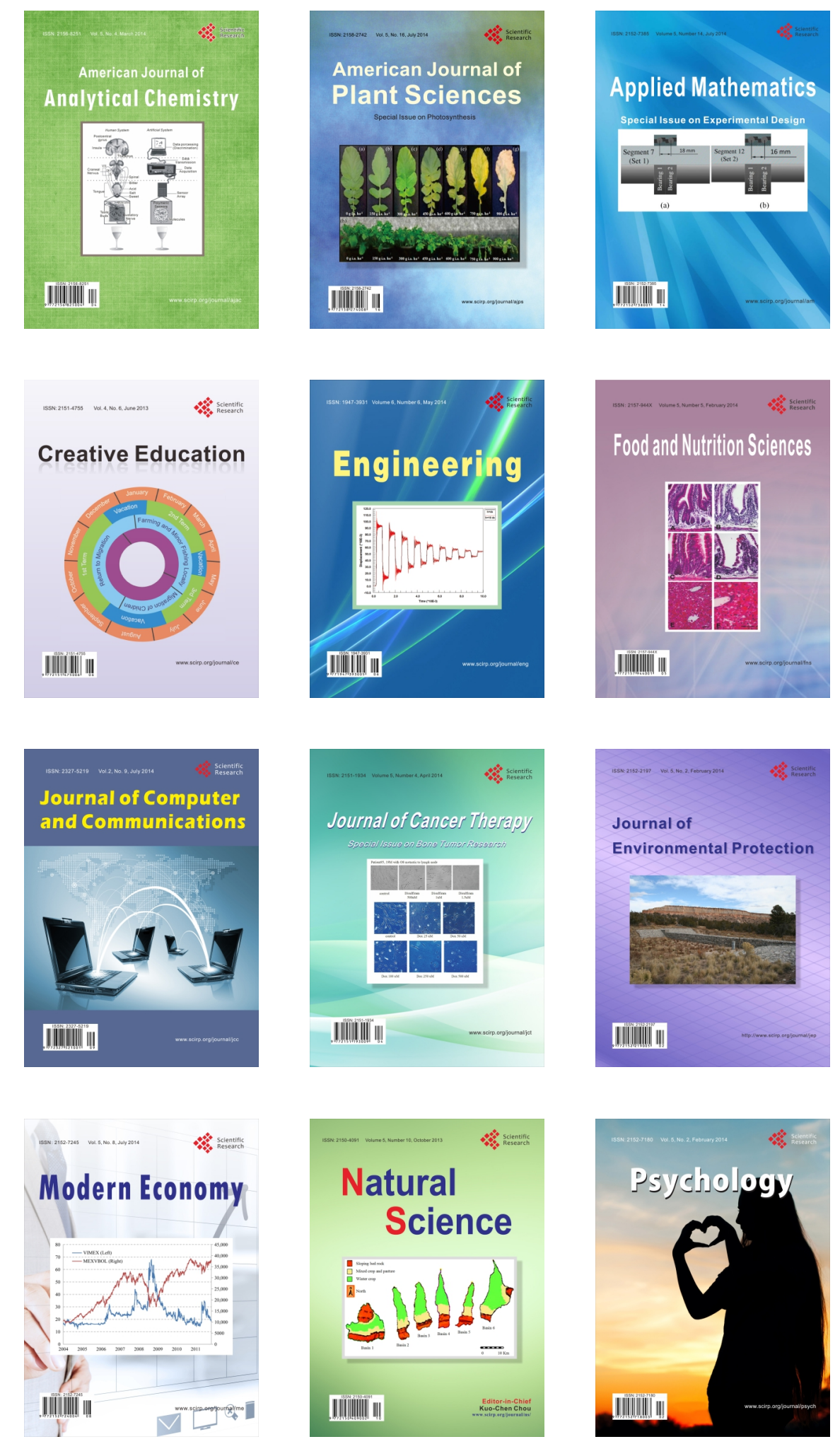